\title{
Using a clinic based creativity initiative to reduce HIV related stigma at the Infectious Diseases Institute, Mulago National Referral Hospital, Uganda
}

\author{
*Neema $\mathrm{S}^{1,2}$, Atuyambe LM $\mathrm{LM}^{2,3}$, Otolok-Tanga E ${ }^{2,3}$, Twijukye $\mathrm{C}^{4}$, Kambugu A ${ }^{4}$, Thayer L ${ }^{4}$, McAdam $\mathrm{K}^{4}$ \\ 1. Makerere University, Department of Sociology and Anthropology P. O. Box 7062 Kampala \\ 2. Research, Communication and Training (RECOT), P.O.Box 671, Kampala, Uganda \\ 3. Makerere University School of Public Health, Department of Community Health and Behavioural Sciences, P. O. Box \\ 7072, Kampala, Uganda \\ 4. Infectious Diseases Institute, Mulago Hospital Complex, P.O.Box 22418, Kampala, Uganda
}

\begin{abstract}
Background: Stigma has been associated with chronic health conditions such as HIV/AIDS, leprosy, tuberculosis, Mental illness and Epilepsy. Different forms of stigma have been identified: enacted stigma, perceived stigma, and self stigma. Stigma is increasingly regarded as a key driver of the HIV/AIDS epidemic and has a major impact on public health interventions.

Objectives: The initiative was to provide activities in the clinic while patients waited to be seen by healthcare professionals. It was envisaged this would contribute to reduction of clinic based stigma felt by clients.

Methods: This was a repeated cross-sectional survey (October-November 2005 and March-April 2007) that was conducted at the Infectious Diseases Institute clinic (IDC) at Mulago, the national referral hospital in Uganda. We utilized quantitative (survey) and qualitative (key informants, focus group discussions) methods to collect the data. Data were collected on stigma before the creativity initiative intervention was implemented, and a second phase survey was conducted to assess effectiveness of the interventions.

Results: Clients who attended the IDC before the creativity intervention were about twice as likely to fear catching an infection as those who came after the intervention. The proportion that had fears to be seen by a friend or relative at the clinic decreased. Thus during the implementation of the Creativity intervention, HIV related stigma was reduced in this clinic setting.

Conclusions: The creativity intervention helped to build self esteem and improved communication among those attending the clinic; there was observed ambiance at the clinic and clients became empowered, with creative, communication and networking skills. Improved knowledge and communication are key in addressing self stigma among HIV positive individuals.
\end{abstract}

Key words: stigma, creativity initiative, HIV/AIDS, IDI, Uganda

African Health Sciences 2012; 12(2): 231 - 239 http://dx.doi.org/10.4314/ahs.v12i2.24

\section{Introduction}

HIV related stigma is widely recognized as a factor that fuels the HIV/AIDS epidemic Jonathan Mann, 1987, Statement at an informal briefing on AIDS to the 42nd session of the United Nations General Assembly. October.. New York), even in the context of Uganda's success story in combating HIV/AIDS. Stigma has been associated with chronic health conditions such as HIV/AIDS, Leprosy, tuberculosis, mental illness, and epilepsy ${ }^{1,2,3,4}$. Stigma has been defined as an undesirable or discrediting attribute, reducing an individual's status in the eyes of society ${ }^{4,5}$.

\begin{tabular}{|l|}
\hline${ }^{*}$ Corresponding author: \\
Stella Neema \\
Department of Sociology and Anthropology \\
Makerere University \\
P. O. Box 7062 \\
Kampala, Uganda \\
Email: sheisim@yahoo.com \\
\hline
\end{tabular}

African Health Sciences Vol 12 No 2 June 2012
Elsewhere, Parker and Aggleton ${ }^{6}$ have argued that stigma must be regarded as a process in which people, out of fear of the disease, want to maintain social control by contrasting those who are normal with those who are different ${ }^{6}$. It is characterized as internal and external and is highly complex, dynamic, and deeply ingrained. The lack of recognition of stigmatizing attitudes, language and discriminatory behaviors and their consequences is a major and basic challenge.

Different forms of stigma have been identified: enacted stigma, perceived stigma or felt stigma, discrimination, participation restriction, and stereotype $^{7}$. Discrimination, which refers to any negative form of distinction, exclusion, or restriction affecting an individual because of a personal characteristic, is an end result of stigmatization and is therefore often described as "enacted stigma" 1,8. Felt or perceived stigma on the other hand, refers to 
real or imagined fear of societal attitudes and potential discrimination, arising from a particular undesirable attribute, disease, or association with a particular group. For example, an individual may refuse to disclose HIV status for fear of the possible negative reactions of family, friends, and community 9 Stigma is increasingly regarded as a key driver of the HIV/AIDS epidemic. Stigma is increasingly recognized to have a major impact on public health interventions. Stigma often leads to delay in presentation to the health services, prolonged risk of transmission, poor treatment adherence, and increased risk of disability and drug resistance ${ }^{10}$.

A key determinant of effective HIVprevention and AIDS care is the existence of a human and supportive environment for people with AIDS $^{11}$. Researchers have documented the negative personal and social implications of AIDS stigma for people living with HIV (PLWH). Some of the negative psychological effects include anxiety, depression, guilt, isolation, disruption of family dynamics, physical and emotional violence, intensification of grief, loss of social support and deterioration of productive relations with health professionals $^{12 .}$

HIV related stigma discourages people from disclosing their status, entering care, and adhering to antiretroviral regimens, all of which represent missed opportunities for prevention. Researchers have alluded to two broad dimensions of stigma as social distancing and attitudes and values towards $\mathrm{PLWH}^{8}$. Hence studies assessing stigma for people living with HIV \& AIDS fall broadly into three main categories: - Perceived stigma, experienced stigma, and internalized stigma. It should be noted that few studies have focused on the actual experience of stigma among PLWH.

Programs aiming at reducing stigma need in particular to be able to measure all the key underlying causes of stigma ${ }^{11}$ as well as identify which causes lead to particular stigmatizing behaviour. The growing recognition of the reduction of HIV stigma as central to effective programs across the HIV/ AIDS prevention to care and treatment continuum is leading to an increasing number of programs focused on stigma reduction ${ }^{8}$.

Despite extensive knowledge regarding the consequences of stigma and discrimination, comparatively little progress has been made in systematically addressing these in public health programs. Many stigma reduction interventions have been carried out, but their effectiveness is often not known $^{10}$.
The effects of stigma on the affected individual include psychological stress and depression, fear, various participation restrictions and increased (risk of) disability and advanced disease. Many negative effects on public health programs and interventions have been reported, including delay in diagnosis and treatment, resulting in continuing risk of disease transmission in the case of infectious diseases and in more severe morbidity and poor treatment prognosis in most conditions ${ }^{13}$.

Concealment may result in continued risk behaviour and failure to embrace preventive behaviour in conditions such as HIV and TB $^{14,15}$ and in poor treatment adherence or default from treatment, as has been reported in leprosy, TB, HIV/ AIDS, mental illness and epilepsy ${ }^{16}$. External stigma leads to internal stigma in the form of negative selfimage. This includes feeling that one is unclean, a bad person, being punished, and expressing feelings of shame and guilt for being HIV positive and self isolation or withdrawal, including hiding HIV status from others ${ }^{17}$.

A study carried out in Mbarara and Kampala in Uganda found that the highest form of stigma was self-stigma, rather than community stigma. It highlights that despite the unique comprehensive and quality services provided by AIDS service organizations, only the most economically desperate seek them out because such organizations do not offer confidentiality in the strictest sense. Since these organizations provide services only to HIV-positive people, the simple act of walking through the door is tantamount to declaring one's sero-positive status to all and sundry ${ }^{18}$.

Widespread care and support for people living with HIV/AIDS co-exists with stigma and discrimination ${ }^{19}$. Fear of casual transmission persists, in part because people feel compelled to adopt extraordinary risk-averse behavior due to their fear of sudden death if infected with HIV. Moral judgments about sexual behavior, as well as the language used about HIV further compound the problem of stigma and discrimination ${ }^{19}$.

The data on stigma is important for:-

- Understanding the situation of people affected by a given condition in a particular area or community, as part of a situational analysis for a public health program

- Monitoring and evaluating the (cost)effectiveness of interventions to reduce stigma in the community. The efficacy of different strategies and interventions could be compared. 
- Strengthening the case of people involved in advocacy on behalf of those stigmatized.

- Research to increase our understanding of more effective stigma reduction interventions

New data can inform the design of programs and tools to reduce stigma ${ }^{20}$. Indeed interventions are being implemented to try to reduce HIV stigma as their primary goal, or as an element of other efforts. Evaluating these programs is essential to learn what works to reduce stigma, and what should be replicated and scaled up.

\section{Changing language, changing self perception} A major part of stigma comprises the internal perception of oneself; and that statement is not intended to minimize the stigmatizing perceptions and actions of others towards the person who feels rejected. The language that a person uses to describe herself/himself $(70 \%$ of our clients are women) dictates how $\mathrm{s} /$ he understands her condition, and her position in relation to others. If individuals see themselves as "patients" then they will automatically assume a position of subservience to medical practitioners who dictate their survival behaviour. The term "client", which was preferred by Kampala's PLWH leaders, is slightly more empowering, but still implies a condition of acquiescence.

There are other options for how to see the people we serve. Based on discussions with our clients, IDI changed its way of talking about those we serve. We now refer to them not as patients or clients, but rather as "mikwano gyaffe" which means "our friends" in the local vernacular, Luganda. This term has a radically different implication; rather than being people who we provide solutions for, these are people who we are in partnership with in the struggle against HIV/AIDS in Uganda.

\section{The creativity initiative at IDI: creating a supportive clinic environment}

Many busy clinics in Africa have a familiar pattern of sombre fatality, where order is a tradition maintained by a nurse, clinical officer or doctor. Patients wait for long periods, moving up a place at a time in the queue to see the care provider, while observing the humanity around them in an amazingly silent vigil, punctuated by children crying. Generally clinics are full of well behaved subservient individuals; their chance of seeing the doctor or nurse or clinical officer increases if they arrive early and if they can pay. Medicines are not always available;

African Health Sciences Vol 12 No 2 June 2012 tests may not be available, and so it helps if payment is an option.

When antiretroviral drugs (ARVs) were first made available in Uganda, demand for care overwhelmed the available facilities. Clinics including the IDI clinic became increasingly busy, waiting times increased and staff became more stressed. After consultation at IDI with staff and patients, a Creativity Initiative was born, led by the Friends. The initiative was first intended to provide activities in the clinic while patients waited to be seen by healthcare professionals. A carpenter made some large board games, music and dance shattered the silence, communal art and crafts engaged many, a group started training in how to develop entrepreneurial skills to gain productive employment, and others provided social and spiritual support in the clinic.

What a contrast to have a Friend orientated clinic; where waiting clients can participate in absorbing activities, see smiling faces and be encouraged by others in the same situation. The wait may be just as long but the experience energising and encouraging (as opposed to de-motivating and fearful).

The creation of a supportive clinic environment does not depend on having a Creativity Initiative; rather the Creativity Initiative helped to bring patients and staff into a more caring relationship that builds the self esteem of both. The process of establishing a supportive Friend-led clinic took several months and cannot be driven by a menu because each community has different human resources. The Creativity Initiative requires creative leadership and consultation with key stakeholders: patients and staff.

\section{Methods \\ Design}

This was a repeated cross-sectional survey that was conducted at the Infectious Diseases Institute clinic at Mulago, the national referral hospital in Uganda. We utilized quantitative and qualitative methods to collect the data. Data collection followed a before and after intervention design.

\section{Setting}

The first survey was conducted in October and November 2005 and the second one took place in March-April 2007 at the Infectious Disease Institute (IDI). Data was collected before the creativity initiative intervention was implemented and a second phase survey was conducted to assess effectiveness of the interventions. 


\section{Data collection methods}

Quantitative: Quantitative data was collected with a semi structured questionnaire with HIV positive clients attending the IDI clinic. Systematic sampling method was applied being guided by the average daily attendance number to determine the sampling interval. About $70 \%$ of respondents were old clients (had been clients for over a year). In each of the surveys we attained a sample size of 400 clients.

Qualitative: Focus group discussions (FGDs) and key informant (KI) interviews were used to collect data.

Focus groups employ a qualitative technique that allows a small group of participants to discuss issues in-depth, led by a moderator using a discussion guide $^{21}$. In addition, key informant interviews were also conducted. Key Informants are people who, because of their position or experience, have knowledge on the topic of investigation ${ }^{23}$. This study was carried out in the IDI clinic at Mulago Hospital. This is a specialized out-patient clinic for HIV and other opportunistic infections. It had a daily attendance of about 350 patients and an overall enrollment over 10, 000 clients at the time of study.

\section{Participants and procedure}

Study participants were HIV positive clients who were sick and had come to access services or were collecting their medication at the clinic. The FGD participants were recruited while they were seeking HIV related services. After explaining the study to the clinic administration, one of the staff would inform possible participants about the study. Participants entered into the study after receiving their service. The objectives of the study were further explained and verbal consent for participation sought. Key informants were purposefully selected on the basis of being providers (medical officer, nurse, counselor, pharmacist or in administration).

The FGD guides were translated from the original English version into the local language (Luganda) by one group of bilingual research assistants (RAs). Another group of RAs translated the Luganda version back to English, and the guide was then compared with the original version. This was done to ensure consistency of meaning in the FGD guide ${ }^{24}$.The FGD guide was pre-tested during one group discussion and thereafter adjusted for the main data collection. Results of the pre-test are not included in the analysis. Research assistants were recruited and trained. All FGDs were tape recorded (with consent from the participants) and transcribed into English. Participants were guaranteed anonymity and instructed not to share individual responses with others. Discussions were facilitated by a moderator who directed the questions and a recorder who took notes. Eight FGDs comprising 75 HIV clients were conducted with men and women separately. FA FGD lasted for about 1.5 hours. Participants were served a soft drink and their transport costs were reimbursed. Topics for discussion were Stigma, Social interactions (patient to patient, provider to patient), fears and experiences, and innovations for quality improvement.

\section{Data Analysis}

Qualitative: The initial step was to read through the transcripts several times while making notes in the transcript. The research team and graduate social science research assistants participated in this process. Disagreements or issues needing further clarity were resolved through discussion and triangulation of data sources. We used FreeMind computer software to generate the key ideas emerging from both the FGDs and the KI interviews. Latent thematic content analysis technique was used. This technique refers to what the text talks about with relationship aspects and involves in-depth interpretation of underlying meanings of text. Data was therefore condensed i.e. shortened without losing quality ${ }^{25,26}$. Open coding was done and codes grouped into categories and then themes identified, as stipulated by Graneheim and Lundman, 200427. For example, codes such as, 'hiding from someone known to the client at the clinic', 'avoiding using clients' entrance at the clinic' 'not registering one's real name at the clinic' generated categories like 'shame and guilt' and subsequently the theme 'felt or perceived stigma'.

Quantitative: Quantitative data was cleaned, entered and analysed using EPI-INFO version 331 software. Uni-variate and Bi-variate analyses were performed. Frequency distribution tables, and cross-tabulations were the main form of presentation and analysis tools for the study. A few tests of significance were carried out to test the difference in proportions and numerical outcomes. Specifically, chi-square tests and odds ratios were used for the proportions.

\section{Ethical considerations}

Verbal consent was obtained from the participants for this client satisfaction survey after explaining the objectives of the study. In addition confidentiality safeguards and potential risks and benefits of the study were explained. Although participants were informed that they could withdraw from the study at any one time none expressed this need.

African Health Sciences Vol 12 No 2 June 2012 


\section{Trustworthiness of the data}

Experienced qualitative and quantitative researchers on the team acted as auditors' through the entire duration of the study.

\section{Results}

\section{Sample characteristics}

Almost half of the respondents for both cross sectional surveys were in the age group 30-39 years. Most of the clients who visited the clinic were: women; married; with formal education; and currently working, for both the surveys. More respondents $(10 \%)$ reported having tertiary education in 2007 compared to only $3.7 \%$ in 2005 . There was an increase in the number of respondents reporting that they were currently working (65\%) in 2007 compared to $50 \%$ in 2006 . Of those currently working there was an increase in respondents earning 50,000 Ug.shs and more compared to those in 2006. Most respondents were old clients (90\%).

HIV related stigma: interactions at the clinic before and after the creativity initiative

Respondents were asked whether they appreciated being by themselves at the clinic; had fears of catching infections; had fears of being touched at the clinic; being seen at the clinic by friends; and whether they had disclosed to persons outside the clinic (table 1)

Table 1: Stigma experienced at the IDI clinic before and after the creativity initiative

\begin{tabular}{|c|c|c|c|c|}
\hline Variable & Yes & No & OR & $95 \% \mathrm{CI}$ \\
\hline \multicolumn{5}{|c|}{ Appreciated keeping to themselves at the clinic } \\
\hline Before creativity Initiative & 27 & 373 & 0.86 & $0.49-1.52$ \\
\hline After creativity Initiative & 31 & 369 & & \\
\hline \multicolumn{5}{|c|}{ Had fears of catching infection at the clinic } \\
\hline Before creativity Initiative & 205 & 195 & 1.81 & $1.35-2.42^{*}$ \\
\hline After creativity Initiative & 145 & 253 & & \\
\hline \multicolumn{5}{|c|}{ Had fears of being touched at the clinic } \\
\hline Before creativity Initiative & 347 & 53 & 1.00 & $0.81-1.32$ \\
\hline After creativity Initiative & 354 & 46 & & \\
\hline \multicolumn{5}{|c|}{ Had fears of being seen at the clinic by friends or relatives } \\
\hline Before creativity Initiative & 74 & 326 & 1.37 & $0.92-2.03$ \\
\hline After creativity Initiative & 57 & 343 & & \\
\hline \multicolumn{5}{|c|}{ Disclosure of HIV status to person outside the clinic } \\
\hline Before creativity Initiative & 369 & 31 & 1.08 & $0.87-1.32$ \\
\hline After creativity Initiative & 343 & 57 & & \\
\hline
\end{tabular}

* Statistically significant

Table 1 shows that clients who attended the IDI Clinic before the creativity intervention were about twice as likely to fear catching an infection than those who came after the intervention $(\mathrm{OR}=1.81, \mathrm{CI}$ : 1.35-2.42). This inhibited their interactions at the clinic. The proportion that had fear of being seen by a friend or relative at the clinic had decreased though this was not statistically significant.

\section{HIV disclosure and concealment pattern}

The respondents reporting disclosure were asked who they had disclosed to. Table 2 presents the responses comparing the pattern before and after the creativity initiative. There was a statistically significant difference when a comparison was made before and after the creativity initiative among those that disclosed to a friend, a spouse and a family member.

For those that had not disclosed, the reasons included; still preparing themselves; had young children; refused by a relative; being too sick and obvious; waiting for an opportunity at church; others had just learnt of their status; and others thought their workmates were aware.

\section{'Experienced stigma' at service points at the IDC}

Table 3 illustrates service points where the clients who indicated poor treatment (handling) had been served. The service points explored included; reception, triage, counselors, doctors, pharmacy, laboratory, and guards. There were varied observations made when the before and after responses are compared. 
Table 2: Persons respondents disclosed to their HIV status

\begin{tabular}{lllll}
\hline Variable & Yes & No & OR & $\mathbf{9 5 \% C I}$ \\
\hline $\begin{array}{l}\text { Disclosed to a friend } \\
\text { Before creativity initiative }\end{array}$ & 149 & 220 & 0.70 & $0.54-0.92^{*}$ \\
$\begin{array}{l}\text { After creativity initiative } \\
\text { Disclosed to spouse }\end{array}$ & 197 & 146 & & \\
$\begin{array}{l}\text { Before creativity initiative } \\
\text { After creativity initiative }\end{array}$ & 77 & 292 & 0.51 & $0.37-0.71^{*}$ \\
$\begin{array}{l}\text { Disclosed to a family member } \\
\text { Before creativity initiative }\end{array}$ & 140 & 203 & & \\
$\begin{array}{l}\text { After creativity initiative } \\
\text { Disclosed to other relative }\end{array}$ & 240 & 129 & 0.76 & $0.60-0.96^{*}$ \\
$\begin{array}{l}\text { Before creativity initiative } \\
\text { After creativity initiative }\end{array}$ & 294 & 49 & & \\
$\begin{array}{l}\text { Disclosed to non-regular partner } \\
\text { Before creativity initiative }\end{array}$ & 202 & 167 & 1.12 & $0.83-1.52$ \\
After creativity initiative & 6 & 165 & & \\
$*$ Statistically significant & 363 & & F-test \\
\hline
\end{tabular}

* Statistically significant

Though there was no statistically significant difference among clients who felt poorly treated at any service point at the clinic; the respondents reported poor handling at the reception which was statistically significant. A statistically significant positive change was observed at the counselor point. It is further noted that the changes regarding poor treatment were not statistically significant at doctors, pharmacy, laboratory points and by the guards (table 3).

Table 3: Experienced stigma at service points at the IDI Clinic

\begin{tabular}{|c|c|c|c|c|}
\hline Variables & Yes & No & $\mathbf{X}^{2}$ & P-value \\
\hline \multicolumn{5}{|c|}{ Felt poorly treated at reception } \\
\hline Before creativity Initiative & 4 & 53 & 27 & $0.000^{*}$ \\
\hline After creativity Initiative & 21 & 17 & & \\
\hline \multicolumn{5}{|c|}{ Felt poorly treated at triage } \\
\hline Before creativity Initiative & 22 & 35 & 0.49 & 0.485 \\
\hline After creativity Initiative & 12 & 26 & & \\
\hline \multicolumn{5}{|c|}{ Felt poorly treated at counselors' rooms } \\
\hline Before creativity Initiative & 16 & 41 & 9.9 & $0.002^{*}$ \\
\hline After creativity Initiative & 1 & 38 & & \\
\hline \multicolumn{5}{|c|}{ Felt poorly treated at doctors' room } \\
\hline Before creativity Initiative & 4 & 53 & 0.99 & 0.257 \\
\hline After creativity Initiative & 5 & 33 & & \\
\hline \multicolumn{5}{|c|}{ Felt poorly treated at the pharmacy } \\
\hline Before creativity Initiative & 4 & 53 & 1.72 & 0.164 \\
\hline After creativity Initiative & 6 & 32 & & \\
\hline \multicolumn{5}{|c|}{ Felt poorly treated at laboratory } \\
\hline Before creativity Initiative & 6 & 51 & 0.81 & 0.306 \\
\hline After creativity Initiative & 2 & 36 & & \\
\hline \multicolumn{5}{|c|}{ Felt poorly treated by guards } \\
\hline Before creativity Initiative & 2 & 55 & 0.17 & 0.527 \\
\hline After creativity Initiative & 2 & 36 & & \\
\hline
\end{tabular}

* Statistically significant 
Qualitative data also showed the type of stigma experienced by clients. Responses from FGDs noted that there was almost no stigma between "friends" or "clients" at IDC, save for a few TB cases that were provided with masks as a preventive measure against spreading to staff and fellow friends. The quotations below clearly illustrate this: -

The peer educators are working on that, that is what we do they are daily sensitized so they understand, everyone's situation. There is no stigma amongst friends. When you reach in this clinic you feel better / you are better off, because some of us come when we were badly off but have improved, so we counsel one another instead. (Female FGD Old Case, IDI).

However, what was mostly noted was felt or perceived stigma at the clinic. It was mainly with clients who knew each other as neighbours in their community where they live or any form of acquaintance. In such cases when they found themselves accessing HIV/AIDS services at the same clinic, they tended to hide from each other.

"Some clients are still stigmatized. For instance I have my immediate neighbours who come here. Usually when they come here, someone has to bide first, lets the first one go away and another one joins the line that is what they do "(KI Dispenser IDC).

Others do not want to associate themselves with the AIDS clinic. In such cases they use staff entrance to enter the clinic instead of that used by clients and do not sit where they will be easily recognized as illustrated by the quote below:

'There are clients who don't want to pass through the general entrance - they find a way of passing through staff entrance and they even have friends who help them get files, they don't want to be associated with those patients or sit at reception... because they don't want others to know that they come here" (KI Receptionist IDC).

In a few cases it was reported that some clients, especially those who are new, do not register at the clinic using their real names for fear of being identified as accessing HIV/AIDS care. Once they see someone they know at the clinic they hide as illustrated by the quotes below.

"There is one man who came here for treatmenthis file was already sorted out and handed over to the reception and already assigned a number, but in the mean time when he was seated waiting, he saw bis neighbour amongst people at the reception, so he came to me as a volunteer and asked me whether there was another door or way where he could secretly pass without being seen by the neighbour in the group. He told me he doesn't want his neighbour to see bim. He quickly ran - quickly went out and off away he was, he did not take the treatment nor was he examined, he only turned up after three days" (Female FGD Old Case, IDI).

"I think it does happen because some of them do not feel that they should get drugs nearer to their place. We have known those who have not used their real names for registering, maybe I can attribute it to a degree of stigma of not wanting to be identified as part of this clinic" (KI Nurse IDI).

Such kind of reactions points to the fact that external stigma can lead to internal stigma in the form of negative self-image, where one expresses feelings of shame and guilt for being HIV positive including not disclosing HIV status and not wanting to be seen by a person who knows the client at a facility that provides HIV/AIDS services.

\section{Discussion}

The primary purpose of this paper was to examine how a creativity intervention in a busy HIV clinic could help to reduce HIV related stigma. The IDIclinic management realized the need to reduce stigma as important for uptake of services and adherence to ART. The institution of the creativity initiative was a broad response to the rapid increase in demand for services across the HIV/AIDS prevention to care and treatment continuum.

Data from this study have revealed that clients who attended the IDC before the creativity intervention were about twice as likely to fear catching an infection as those who came after the intervention. The proportion that feared to be seen by a friend or relative at the clinic decreased. Therefore, during the implementation of the Creativity intervention HIV related stigma was reduced in this clinic setting.

Our study concurs with studies on stigma by Berger et al 2001 as it was found that external stigma may lead to internal stigma in the form of negative self-image ${ }^{17}$. Perceived stigma was also evident as some clients did not want to be seen at the clinic especially by those who knew them, as they wanted to conceal their status for fear of discrimination.

The creativity initiative may have contributed to the increase of disclosure among the "friends" leading to reduced HIV related stigma. Our study showed that there was a statistically significant difference when a comparison was made of before 
and after creativity initiative among those that disclosed to a friend, a spouse and a family member. The dimensions and impact of stigma are likely to change as a person has more experience of living with HIV and is provided with opportunities to share their HIV status at the clinic, as the case in this initiative. This is in line with other studies ${ }^{4,28}$ who implicated stigma as contributing to poor treatment adherence or default from treatment in those with leprosy, TB, HIV/AIDS, mental illness and epilepsy ${ }^{16,28}$

Every family in Uganda is affected by HIV; no stratum of society is untouched. A medical paradigm will not be sufficient for meeting the range of needs faced by HIV-positive people. Clearly, HIV/AIDS is more than a medical problem, it is a multi-sectoral challenge to society. Once they are diagnosed as HIV-positive, people face stigma; rejection by family; loss of jobs and poverty. Treatment providers can offer little more than compassion in these areas.

As the IDI clinic embraced a new relationship with those they serve, we noticed a dramatic shift in the behaviour of staff and clients in their commitment to helping to find solutions to challenges. Friends are now routinely approaching IDI staff about better ways that the clinic might be organized (and indeed there is evidence from this study that they are able to be more critical of unacceptable treatment). They are also gaining the courage and confidence to tell their poignant stories in public, and are beginning to take responsibility for care and encouragement of new Friends. But the most dramatic change is that Friends are now expressing interest in leading the development of IDI's prevention and treatment adherence support activities. This shift is critical if there is to be a chance of effectively addressing the epidemic.

\section{Conclusions}

Given the findings from this study, one cannot imply causality because many things changed for individuals over the time of the study. However, this study revealed that a clinic based creativity intervention was associated with a dramatic change in the observed ambiance of the clinic. At the same time, those living with HIV were empowered, by recognizing their creative skills, communication and networking improved, people received training and income generation increased. Some measures of stigma were observed to change positively during the study period, (associated with but not necessarily ascribable to the Creativity Initiative). Rather than reinforcing stories of stigma, which abound in the community, this intervention helped to build selfesteem and improve communication. Awareness of the issues around stigma remains a key issue through education and sensitization programs. Counseling is important as a key measure since it reduces self-stigma and encourages positive living. Other measures that help to reduce stigma include seeking appropriate care, joining post test clubs, disclosure of one's HIV status, the level of empathy and concern shown by health staff and by the community and provision of social support services. By examining the effects of an HIV related stigma reduction intervention, best practices and lessons learnt can be replicated elsewhere in similar or different settings. The Creativity Initiative has indeed provided an avenue for empowerment of "friends" and an inroad towards reduction of HIV related stigma in a clinic setting.

\section{References}

1. Jacoby A, Gorry J, Gamble C, Baker GA .Public knowledge, private grief: a study of public attitudes to epilepsy in the United Kingdom and implications for stigma. Epilepsia 2004; 45: 14051415.

2. Nyblade L, Pande, R., Mathur, S., MacQuarrie, K., Kidd, R., Banteyerga, H, (2003) Disentangling HIV and Stigma in Ethiopia, Tanzania and Zambia. . International Centre for Research on Women.

3. Piot P (2001) Stigma, bias present barriers in fight against AIDS pandemic. AIDS Policy Law 16: 5 .

4. Weiss MG, Ramakrishna J, Somma D. Healthrelated stigma: rethinking concepts and interventions. Psychol Health Med 2006; 11: 277 287.

5. Goffman E ( 1963) Stigma: Notes on the management of spoiled identity. Garden City, NY: Anchor Books.

6. Parker R, Aggleton P. HIV and AIDS-related stigma and discrimination: a conceptual framework and implications for action. Soc Sci Med 2003; 57: 13-24.

7. Van Brakel WH. Measuring health-related stigma - a literature review. Psychol Health Med 2006; 11: 307-334.

8. Nyblade LC. Measuring HIV stigma: existing knowledge and gaps. Psychol Health Med 2006; 11: 335-345. 
9. Brown L, Macintyre K, Trujillo L. Interventions to reduce HIV/AIDS stigma: what have we learned? AIDS Educ Prev 2003; 15: 49-69.

10. Heijnders M, Van Der Meij S. The fight against stigma: an overview of stigma-reduction strategies and interventions. Psychol Health Med 2006; 11: 353-363.

11. Ogden J, Nyblade L (2005) Common at its Core: HIV-Related Stigma Across Contexts. International Centre for Research On Women (ICRW).

12. Greeff M, Uys LR, Wantland D, Makoae L, Chirwa M, et al. Perceived HIV stigma and life satisfaction among persons living with HIV infection in five African countries: a longitudinal study. Int J Nurs Stud 2010; 47: 475-486.

13. Piot $P$, Coll Seck AM International response to the HIV/AIDS epidemic: planning for success. Bull World Health Organ 2001; 79: 1106-1112.

14. Adetunji J, Meekers D Consistency in condom use in the context of HIV/AIDS in Zimbabwe. J Biosoc Sci 2001; 33: 121-138.

15. Rahlenbeck $S$, Uhagaze B. Intentions to use condoms in Rwandan secondary school students. AIDS Care 2004; 16: 117-121.

16. Weiss L, French T, Finkelstein R, Waters M, Mukherjee R, et al. HIV-related knowledge and adherence to HAART. AIDS Care 2003; 15: 673679.

17. Berger BE, Ferrans CE, Lashley FR Measuring stigma in people with HIV: psychometric assessment of the HIV stigma scale. Res Nurs Health 2001; 24: 518-529.

18. UNAIDS (2000) HIV/AIDS Related Stigmatisation, Discrimination and Denial: Forms, Contexts and Determinants. Research studies from Uganda and India. Geneva.
19. Otolok-Tanga E, Atuyambe L, Murphy CK, Ringheim KE, Woldehanna S. Examining the actions of faith-based organizations and their influence on HIV/AIDS-related stigma: a case study of Uganda. Afr Health Sci 2007; 7: 55-60.

20. Kidd R, Clay S (2004) Understanding and Challenging HIV Stigma: Toolkit for Action Washington, DC.

21. Patton MQ Qualitative research and evaluation methods. California: Sage Publications, Inc. 598 p.

22. Lakshman M, Charles M, Biswas M, Sinha L, Arora NK (2000) Focus group discussions in medical research. Indian J Pediatr 2002; 67: 358362.

23. Newman WL (2003) Social research Methods: Qualitative and Quantitative approaches; Lasser J, editor. Boston: Pearson Education Inc. 584 p.

24. Lee JA, More SJ, Cotiw-an BS Problems translating a questionnaire in a cross-cultural setting. Prev Vet Med 1999; 41: 187-194.

25. Downe-Wamboldt B. Content analysis: method, applications, and issues. Health Care Women Int 1992; 13: 313-321.

26. Kondracki NL, Wellman NS, Amundson DR. Content analysis: review of methods and their applications in nutrition education. J Nutr Educ Behav 2002; 34: 224-230.

27. Graneheim UH, Lundman B. Qualitative content analysis in nursing research: concepts, procedures and measures to achieve trustworthiness. Nurse Educ Today 2004;24: 105-112.

28. Singer S. HIV, stigma, and rates of infection: more complicated than Reidpath and Chan suggest. PLoS Med 2007; 4: e51; author reply e44 